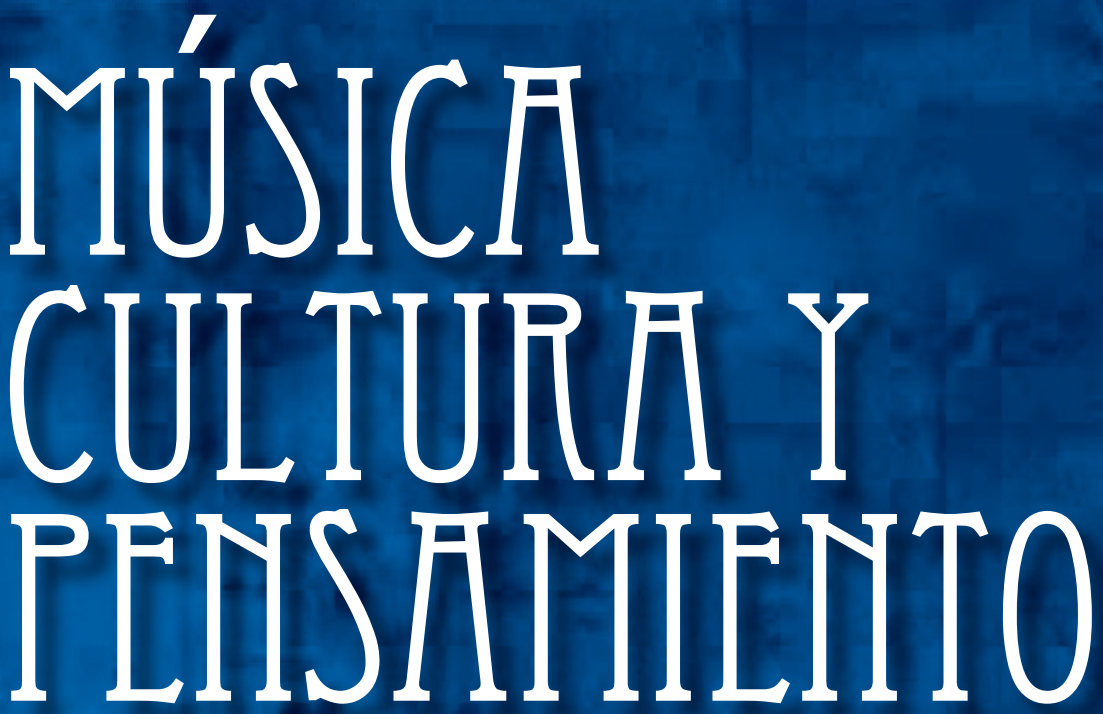

Revista de investigación de la Facultad de Educación y Artes del Conservatorio del Tolima

VOL. VIII N.o 8 - Noviembre 2019
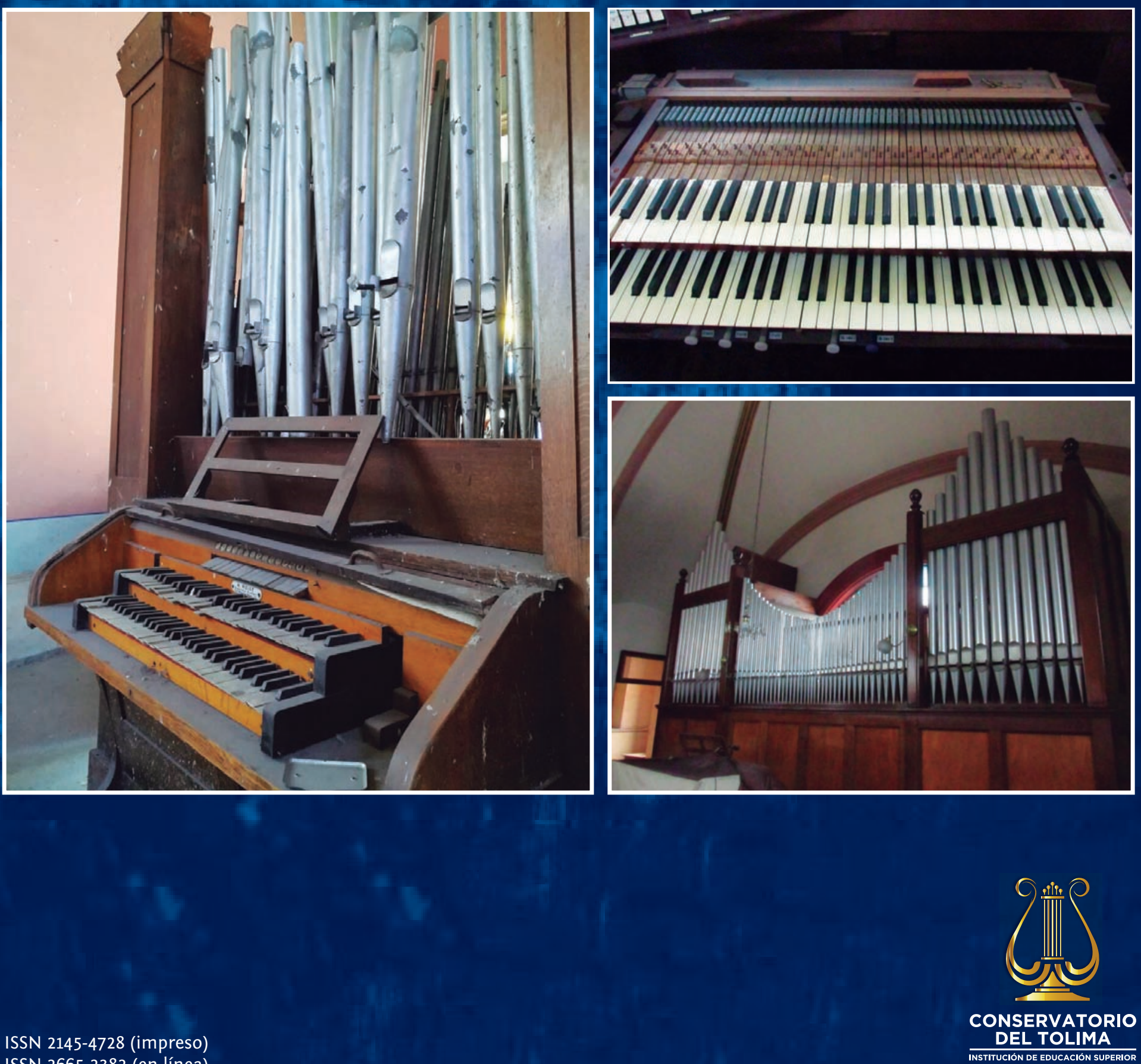


\section{Evidencias de la recepción del bambuco colombiano en Yucatán ${ }^{1}$ (1908-1920)}

Por: Claudio Ramírez Uribe ${ }^{2}$

Artículo de investigación

Recibido: 15 de junio de 2018

Aceptado: 15 de septiembre de 2018

Para citar este artículo/To reference this article: Ramírez, C. (2019). Evidencias de la recepción del bambuco colombiano en Yucatán (1908-1920). Música, Cultura y Pensamiento, 8(8), 63-80.

1 Este artículo está basado en las ideas principales de una investigación más amplia de análisis de los procesos históricos y musicológicos sobre la relación musical entre Colombia y Yucatán.

2 Egresado del Técnico en Música de la Universidad de Guadalajara (2014) y de la Licenciatura en Música por la Universidad Veracruzana (2018). Ha sido publicado por revistas especializadas en culturas populares y música. Ha sido conferencista y ponente en México y Colombia. De agosto a enero de 2017 realizó una estancia de Movilidad en la Universidad Antonio Nariño en Colombia donde fue beneficiario de la beca PAME. Se ha presentado como pianista en México y Colombia, donde también se han estrenado sus composiciones. Actualmente, se encuentra laborando como asistente de investigación en el proyecto "Oraloteca Jarocha” dentro del Programa de Desarrollo Cultural del Sotavento. eltopocegatonii@hotmail.com.

\section{Evidences of the Colombian bambuco reception in Yucatán (1908-1920)}

\begin{abstract}
Resumen
Esta colaboración propone una revisión de las primeras evidencias del bambuco colombiano en la península de Yucatán (grabaciones y ediciones de partituras). Con esto, no solo se muestra el primer contacto musical grabado y editado entre ambas culturas (ocurrido en 1908 por el dueto de Pelón y Marín), sino que también mediante un análisis más profundo, se demuestra que, a partir de dichas evidencias, se desarrollaron dos tradiciones musicales paraleles con el bambuco como nexo común.
\end{abstract}

Palabras clave: bambuco, Colombia, Yucatán, presencia, grabaciones, ediciones.

\begin{abstract}
This collaboration proposes a revision of the earliest evidences of the Colombian bambuco in the Yucatán peninsula (recordings and sheet music editions). This not only shows that first recorded an edited musical contact between these two cultures (happened in 1908 by the Pelón and Marín duo), but also, by a thicker analysis, it's shows that two musical traditions will be developed after those evidences, linked in between by the bambuco.
\end{abstract}

Keywords: bambuco, Colombia, Yucatán, presence, recordings, editions. 
Evidencias de la recepción del bambuco colombiano en Yucatán

(1908-1920)
MÚSICA, CULTURA Y PENSAMIENTO • NOVIEMBRE 2019

VOL. VIII(8) |63-80. ISSN- 2145-4728; ISSN-E 2665-2382

\section{Introducción}

$\mathrm{H}$

aciendo una revisión histórica del árbol genealógico de la canción yucateca,

veremos que sus antecedentes radican en culturas y geografías diversas, lo cual ha sido ampliamente estudiado y difundido. En este sentido, esta colaboración hace un énfasis en uno de estos antecedentes en particular: el colombiano, del cual, la evidencia señala que hace su arribo a Yucatán vía Cuba en la primera década del siglo xx.

La inaccesibilidad geográfica de la península yucateca -esto es por las dificultades de atravesar las selvas, sierras y pantanos del sureste mexicano y que fue abierta hasta hace relativamente poco tiempo-, provocó que se desarrollara una identidad regional bastante particular dentro de la sociedad y cultura de Yucatán.

Esta aparente dificultad de relacionarse con el resto del territorio mexicano, provocó que, desde tiempos coloniales e incluso precolombinos, que los habitantes de la península buscaran establecer nexos con la región insular del Caribe. Los tratos comerciales entre agentes locales y extranjeros (estadounidenses, europeos y cubanos, sobre todo) irán dibujando los trazos del armazón cultural yucateco, obviamente con una gran mixtura del pasado maya local.

Este gran aparato económico y cultural peninsular tuvo su gran detonante hacia mediados del siglo xıx, aproximadamente; es a partir de este periodo en el que se comienza a explotar y a exportar la fibra del henequén, lo que propició el nacimiento de una oligarquía regional, cuyo eje principal estaba apuntalado en la ciudad de Mérida, ávida por europeizarse y disfrutar en sus tertulias del romanticismo francés y de los ritmos de salón cubanos como la habanera o el danzón.

Desde el punto de vista musical, esto puede comprobarse dentro del fenómeno llamado Trova yucateca, el cual es alimentado, precisamente, por influencias extranjeras asimiladas por músicos locales y que fue consolidándose a partir de los años veinte del siglo xx, como la más conocida expresión musical de la península, y que se conformó por tres géneros principales: el bolero yucateco, la clave yucateca y el bambuco yucateco.

La influencia musical cubana estuvo presente de manera importante en la región por lo menos setenta años antes y fue cultivada por compositores locales, lo cual se constata en la copiosa producción de guarachas, habaneras y danzas firmadas por autores yucatecos. Este gran intercambio musical entre la isla de Cuba y la península de Yucatán explica el nacimiento de los géneros del bolero yucateco y la clave yucateca que es una homóloga de la llamada criolla cubana.

Por otro lado, el caso de la presencia colombiana que se ve representada en ese triunvirato musical yucateco por el bambuco, tuvo una introducción mucho más tardía a los salones y salas de concierto de la ciudad de Mérida y además de tardía, breve y contundente; pues en poco más de diez años, los duetos colombianos lograron impactar de tal manera dentro del gusto musical local, que a partir de ese contacto, los compositores yucatecos realizarían una parte importante de su producción en el género más difundido de la región andina colombiana: el bambuco.

Las evidencias de este contacto se ven materializadas en las grabaciones dejadas por el dueto antioqueño de Pelón y Marín en 1908, la edición de bambucos por los artistas locales Filiberto Romero y Luis Rosado Vega en 1909 y el posterior contacto entre el dueto de Wills y Escobar con Ricardo Palmerín durante la gira del dueto en la ciudad de Mérida 
en 1919. Este contacto fue, precisamente, el empuje definitivo para el bambuco en Yucatán, pues a partir de este momento nace la tradición bambuquera en la península.

Por tanto, en esta colaboración se presenta una revisión metodológica de fuentes historiográficas, tanto colombianas como mexicanas, complementadas con el correspondiente trabajo de campo realizado en Colombia mediante entrevistas a los músicos Germán Darío Pérez y Luis Fernando León, especialistas en los géneros andinos de su país.

En Yucatán, dicho trabajo de campo se ve reflejado en la revisión de archivos musicales de donde se extrajeron las fuentes originales (Cancionero de Chan Cil); necesarias para realizar la comparativa entre las primeras evidencias materiales de música colombiana en la región con las tradiciones musicales tanto colombiana como con la posterior yucateca en torno al bambuco.

Esto último con la intención de corroborar si fueron estas evidencias materiales las únicas bases en las que se cimentaría el bambuco en Yucatán o si hubo algún otro factor importante para desencadenar la producción de compositores locales de bambucos con características musicales propias (como la oralidad). En consecuencia, la información fue dispuesta y será presentada de la siguiente manera:

- Una panorámica breve del género del bambuco en Colombia, lo que permitirá tener un paradigma musicológico e histórico que se relacionará a lo ocurrido en Yucatán.

- Revisión del cómo se fue desarrollando la carrera artística del dueto de Pelón y Marín y cómo es que dicho desarrollo laboral los condujo a Yucatán.

- Una panorámica breve del estado socioeconómico y cultural de la ciudad de Mérida al momento de la llegada de Pelón y Marín.

- La gira en Mérida y la revisión de las primeras evidencias físicas de la presencia musical colombiana en la región peninsular; las grabaciones y las ediciones de partituras realizadas en México de los géneros colombianos.

- El contacto y la relación que sostuvieron los trovadores Wills y Escobar con Ricardo Palmerín en 1919 y cómo de este encuentro se comenzó a formar una tradición bambuquera en Yucatán con diferencias importantes. Esto se demuestra por la comparación de patrones de acompañamientos rítmicos básicos del bambuco colombiano con un bambuco del compositor yucateco Ricardo Palmerín.

\section{Breve reflexión sobre el bambuco colombiano}

La diversidad musical colombiana es tan amplia como los mismos paisajes y geografías del país sudamericano. Cada una de las regiones geográficas de Colombia posee características musicales únicas, que las hacen bastante diferenciables entre sí; no obstante, siendo la más amplia ${ }^{3}$ y donde se ubican ciuda-

3 Siguiendo la delimitación de Germán Darío Pérez, quien indica que inicia en el departamento de Nariño en la frontera con Ecuador y termina en el departamento de Norte de Santander, frontera con Venezuela (G. Pérez, comunicación personal, 28 de agosto de 2017). des de gran importancia en el país (como Bogotá o Medellín), la región andina fue durante largos años el núcleo de la identidad musical nacional colombiana, y como parte central de esta identidad musical, el bambuco desempeñó un papel fundamental.

Lo interesante sobre el discurso historiográfico e histórico del bambuco, es ir develando cómo se fue consolidando en este "elemento de identidad nacional"; saliendo del territorio andino hasta convertirse en el "aire nacional colombiano". Podemos ver que a lo largo de la historia colombiana el bambuco se ha hecho presente: encontramos referencias de una danza llamada de esta manera desde las 
Evidencias de la recepción del bambuco colombiano en Yucatán

(1908-1920)
MÚSICA, CULTURA Y PENSAMIENTO • NOVIEMBRE 2019

VOL. VIII(8) |63-80. ISSN- 2145-4728; ISSN-E 2665-2382 guerras de independencia neogranadinas, pues en 1819, el general Francisco de Paula Santander escribe una carta a su compañero, el general París (acantonado en Popayán), donde se menciona el bambuco (Miñana, 1997). Del mismo modo, las crónicas militares narran que, al triunfo de la batalla de Ayacucho, el regimiento de Voltígeros de la Guardia interpretó un bambuco, posiblemente un bambuco de la región de Nariño conocido como La Guaneña (Ocampo, 1990).

Sin embargo, y pese a que los ejércitos libertadores acompañaban sus marchas con bambucos, este género fue estigmatizado a lo largo del siglo xix por la clase acomodada de la nueva nación colombiana. Esto se debió a sus orígenes que lo asocian a los ritmos afro e indígenas de la región del Valle del Cauca (Santamaría, 2014). No obstante, gracias a la difusión que de él dieron los movimientos de los ejércitos, se pudo diseminar a lo largo de la región andina (Santamaría, 2014), diversificando sus estilos e instrumentación.

En las regiones del Tolima y el Huila, por ejemplo, se favorece el uso de la tambora y otros instrumentos de percusión para su ejecución; mientras que en la región de Antioquia, Cundinamarca, Santander o Boyacá proliferó el uso de cordófonos de pulsación, lo que ayudará a que, con el tiempo y con la labor de músicos tanto empíricos como académicos, se fuera desarrollando el llamado trío de cuerdas colombiano: tiple, bandola y guitarra.

A mediados del siglo xix, se comienzan a cantar coplas al ritmo del bambuco con el acompañamiento de tiples y guitarras y es gracias a esta inquietud musical que, en centros urbanos de la región andina, surge el dueto bambuquero (Santamaría, 2014). Para finales del siglo xix, y en gran medida gracias a la labor del bandolista y compositor Pedro Morales Pino (1863-1926), los ritmos andinos comienzan poco a poco a tener un mayor impacto en el gusto de las clases acomodadas. Pues es por el bambuco cantado de los duetos, que se logra la fusión de elementos "cultos", como la poesía de escritores como Julio Flórez y las expresiones musicales "populares", como el bambuco mismo.

Posiblemente son cuatro los factores de mayor incidencia para que el bambuco se convirtiera en el aire nacional colombiano. El primero, como lo comentó el maestro Luis Fernando León, en el cambio del siglo xIx al xx, los compositores comienzan a escribir en el pentagrama los ritmos andinos colombianos, en especial Pedro Morales Pino (L. León, comunicación personal, 19 de septiembre de 2017); el segundo, es la gran proliferación de conjuntos musicales especializados en los ritmos andinos dentro de los grandes centros urbanos e incluso rurales, cuyo rango de acción iba desde la tertulia de fin de semana hasta presentarse en los grandes teatros ${ }^{4}$ y fiestas populares de la región (Rendón, 2009); el tercero, es el uso que le dieron al bambuco los miembros del grupo liberal de La Gruta Simbólica como vehículo de protesta durante los años previos y durante la guerra civil conocida como la Guerra de los Mil Días (Azula, Rodríguez y León, 2011:); la cuarta y última tiene que ver con la gran popularidad y difusión que tuvieron durante este periodo los duetos de cantantes acompañados generalmente por tiple y guitarra (conocidos también como "duetos bambuqueros").

Cabe aclarar que, a pesar del nombre de "duetos bambuqueros", estas agrupaciones también interpretaban otros géneros de la región andina, tales como el pasillo, la danza, el bunde y la guabina, entre otros; repertorio compartido con los conjuntos de cuerdas y las estudiantinas (Barriga, 2005), por ejemplo.

Igualmente, a principios del siglo xx se van a consolidar los dos subgéneros del bambuco: el cantao' y el instrumental. Ambas variantes pueden escribirse en compás de tres cuartos o en seis octavos, pues el bambuco presenta la característica sesquiáltera vertical a lo largo de su ejecución (uso del compás de 3/4 con el de 6/8 de manera simultánea). La diferencia radica en que el bambuco instrumental consta de tres secciones (A-B-C) y es preferentemente para bailar (G. Pérez, comunicación personal, 28 de agosto de 2017). A su vez, el bambuco cantao' consta de dos secciones (A-B), cuya forma de interpretarse suele ser el mismo que el de la forma canción $A A B B$, $A B A B, A B B A$, etc. (L. León, comunicación personal, 19 de septiembre de 2017) (véanse figuras 1 y 2).

Este bambuco fue el que se importó a la península yucateca en 1908 por el dueto antioqueño de Pelón y Marín y, como veremos, gozó de un éxito importante; probablemente, porque para la época en cuestión, tanto en Colombia como en Yucatán, se cultivaban expresiones musicales similares, refiriéndose al menos al uso de duetos de cantantes con acompañamiento instrumental.

4 Un ejemplo de esto es la presentación de la Lira Colombiana
de Morales Pino en el Teatro Maldonado en 1884 (hoy Teatro Colón) (Azula et al., 2011) 


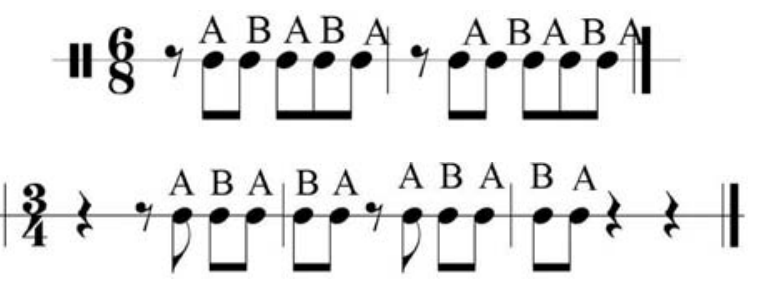

Figura 1. Patrones básicos para el acompañamiento de un bambuco en guitarra tanto en seis octavos como en tres cuartos

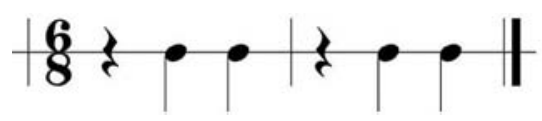

Figura 2. Patrón básico del bajo en un bambuco en seis octavos

\section{Pelón y Marín y la gira que los llevó a la historia}

Para finales del siglo xIx, y en los primeros años del $x x$ hay un gran incremento de la actividad musical en la región andina colombiana. El desarrollo tanto del "dueto bambuquero" como el de la estudiantina (Azula et al., 2011) comienza a popularizarse en toda la región, sobre todo en Bogotá (Londoño, 2015). Las tertulias, retretas y conciertos, que eran populares en todos los estratos sociales, aunque pocas veces se mezclaban entre ellas, crean una gran demanda de estos conjuntos y sus repertorios, lo que ofrecerá un mercado y una opción de ingresos bastante atractiva para la gran población de clase media y obrera de las ciudades de la zona andina.

Los músicos de tiempo parcial comienzan a encontrar mayores opciones laborales como músicos, tal es el caso de la Lira Antioqueña, por dar un ejemplo (Azula et al., 2011): individuos que, como se dijo en el párrafo anterior, poseían suficientes conocimientos musicales como para tener una entrada alternativa de ingreso económico al que le pudiesen brindar sus oficios.

Todo este gran movimiento musical andino colombiano se va configurando a la par de la innovadora importación de los fonógrafos y las primeras grabaciones en 78 r.p.m. a Colombia. Esta llegada de los aparatos de reproducción sonora fue rápidamente apreciada tanto por los músicos locales como por el público que los escuchaba, en especial de las grandes ciudades (Azula et al., 2011).

Por tanto, la gran carrera por ser el primer artista o conjunto en grabar entre los músicos colombianos estaba comenzado (L. León, comunicación personal, 19 de septiembre de 2017). Se debía llegar al mercado de la grabación sonora lo más rápido posible; había que dominar este nuevo nicho mercantil.

Sin embargo, la búsqueda de espacios para dicha grabación por parte de los músicos colombianos debía ser realizada fuera de su país, pues no existían en Colombia sucursales de las compañías disqueras (como las estadounidenses Columbia y RCA Víctor, que sí tenían oficinas en México o Cuba), mucho menos agencias o compañías nacionales (L. León, comunicación personal, 19 de septiembre de 2017).

En este sentido, no parece haber dudas en señalar a los antioqueños Pelón Santamarta y Adolfo Marín “Pelón y Marín" como los primeros colombianos en llegar a las salas de grabación, siendo así los iniciadores de la comercialización de la música colombiana en materiales sonoros. Lo interesante es el cómo llegaron a la mencionada grabación, pues para tal propósito, tuvieron que diseñar una gira por varios países americanos para escalar el continente hasta los Estados Unidos, con la intención de tocar las puertas de las compañías discográficas. No obstante, antes de empezar a hablar sobre esta gira, creo importante mencionar cómo se fue conformando la unión de estos dos músicos de la región andina colombiana.

El dueto es formado en 1903 (Azula et al., 2011), por Pedro León Franco Rave y Adolfo Marín, ambos músicos de tiempo parcial, pues eran sastres de profesión; no obstante, hay mucho más que decir de este par de sastres-músicos.

Además, el verdadero nombre de Pelón Santamarta era aparentemente Pedro León Franco Rave, siendo Pelón Santamarta su nombre artístico. No obstante, el origen del mote de "Pelón" suscita algunas dudas; por un lado, el maestro Fernando León sugiere que el mote de "pelón" proviene de la forma en que se les llamaba a los niños inquietos y traviesos en la Medellín de las últimas décadas del siglo xIx (L. León, comunicación personal, 19 de septiembre de 2017). Por otro, Orlando Ramírez Casas señala que el apodo viene de familia, pues uno de sus hermanos menores, al no poder pronunciar correctamente el nombre de Pedro León, lo llamaba "pelolón", lo que a la larga se acortó a solo "pelón” (Ramírez, 2017).

En cuanto al origen del "Santamarta" era quizá un homenaje a los orígenes de su padre, llamado Pedro León Velásquez (Portaccio, 1995), hijo de Francisca Franco proveniente de la región de Santa Marta y que fue llevado a Antioquia al ser adoptado por un 
Evidencias de la recepción del bambuco colombiano en Yucatán

(1908-1920)
MÚSICA, CULTURA Y PENSAMIENTO • NOVIEMBRE 2019

VOL. VIII(8) |63-80. ISSN- 2145-4728; ISSN-E 2665-2382 liberto antioqueño Ilamado Escolástico Velásquez (Azula et al., 2011).

Por otro lado, Adolfo Marín era conocido como sastre; sin embargo, se cree que la verdadera profesión de este "sastre" era la de agente de inteligencia de la época (L. León, comunicación personal, 19 de septiembre de 2017), cosa bastante curiosa, pero posible dentro del mundo de la bohemia; además de que para la época en cuestión ${ }^{5}$, no era de extrañar que las tertulias y los grupos artísticos estuvieran bien vigilados en busca de ideas subversivas o que pusieran en entredicho las políticas gubernamentales.

Después de formarse en Medellín, el dueto viaja a Bogotá en busca de fortuna y para introducirse de lleno en la vida musical capitalina (L. León, comunicación personal, 19 de septiembre de 2017). No obstante, se encuentran con un mercado copado por duetos bogotanos, entre los que pueden contarse los duetos de Ricardo Cuberos y Luis Romero, Carlos Romero y Eduardo Baquero, Daniel Uribe y Justiniano Rosales, José María "el Chato" Escamilla y Carlos Arenas, Arturo Patiño y Joaquín Forero, Alejandro Wills y Alberto Escobar, Hipólito Rodríguez "Cabo Polo” y Joaquín Rodríguez, y Carlos Espinosa Páez y Helio Cavanzo (Azula et al., 2011).

Sin embargo, este contacto con los músicos de la capital colombiana, permitió que el dueto de Pelón y Marín aprendiera una gran cantidad de canciones, propias del gusto de la ciudad, particularmente bambucos (L. León, comunicación personal, 19 de septiembre de 2017). Este nuevo repertorio es el que les permitirá tener un primer impacto en los teatros y escenarios bogotanos y luego en el interior del país.

Eventualmente, el éxito dentro de Colombia les proporcionó el dinero suficiente para emprender un viaje que tenía como objetivo la ciudad de Nueva York, como ya se comentó líneas arriba, con la intención de llegar a las casas discográficas estadounidenses y entrar en el mercado de la música grabada.

La ruta trazada se inicia en 1907, la cual comenzó en la Costa Atlántica colombiana y de ahí viajan a Panamá, Guatemala, Jamaica y Cuba (Portaccio, 1995). Parece que durante la gira por Centroamérica y el Caribe no tienen la acogida esperada, por lo que en La Habana, ya con el nombre de "Los Trovadores

\footnotetext{
5 Colombia acababa de salir de la etapa final de la guerra civil
} más cruenta de su historia: la Guerra de los Mil Días.
Colombianos", se unen a la compañía de variedades de Raúl del Monte (Azula et al., 2011), la cual realiza un viaje a México, más concretamente a la península yucateca en 1908. Es, precisamente, en este viaje donde su éxito se hace mayúsculo.

Son gratamente recibidos por el público yucateco; y es tal la buena acogida a sus presentaciones, que son invitados a grabar para el sello Columbia en la ciudad de México. El furor por la música colombiana era tan grande que la disquera graba con el dueto cuarenta temas (Azula et al., 2011), en su gran mayoría bambucos tales como El enterrador y Ya ves.

Posteriormente a la gira consagratoria por México y Yucatán, el dueto se desintegra: Pelón regresa a Colombia en 1913, donde continúa su labor de músico, a la vez de que se inicia en el negocio de la producción ilegal de alcohol, por lo que es aprendido; ya en la cárcel, retoma su labor de sastre (Portaccio, 1995). Adolfo Marín permanece en México ${ }^{6}$ (Ramírez, 2017) hasta su muerte en 1932 (Portaccio, 1995).

¿Pero cómo se encontraba la ciudad de Mérida, capital del estado mexicano de Yucatán, a la llegada de "Los Trovadores Colombianos"? ¿Existieron factores socioeconómicos importantes para explicar el éxito del dueto colombiano en la ciudad más importante del sureste mexicano?

\section{La Mérida que recibió a Pelón y Marín}

En el momento en que Pelón y Marín hacen su arribo a la península yucateca existía una gran bonanza económica gracias al desarrollo de la industria del henequén, la cual había comenzado a incrementarse desde mediados del siglo xix en la región. Coincidentemente, el cenit de la producción del también llamado "oro verde" es paralelo con el gobierno nacional del general Porfirio Díaz, el cual buscaba reactivar la economía mexicana, lo que incentiva la producción y exportación a gran escala del henequén, como lo señala Cervera (2007):

Cobró particular impulso en la década de los ochenta del siglo xIx, fue acrecentándose en las siguientes y permitió cimentar el dominio de un reducido grupo de terratenientes sobre la economía local, aunque asentado en un sistema de monocultivo que a la larga mostraría su fragilidad (p. 83).

6 Otros autores dicen Centroamérica (Ramírez, 2017). 
Este auge económico se reflejó de manera directa en el crecimiento urbano de Mérida, pues la capital albergaba a las familias más poderosas de la región. Las últimas dos décadas del siglo xix son testigos de la construcción de nuevas colonias, así como el saneamiento de las calles del centro de la capital yucateca. Igualmente se adoquinan algunas calles de la ciudad y se inaugura el alumbrado público (Cervera, 2007).

La vía férrea y las comunicaciones sufren también este empuje de modernidad a lo largo del sureste mexicano, ya que entre 1881 y 1904 se instalan 800 $\mathrm{km}$ de vías férreas, conectando las ciudades de Mérida, Puerto Progreso, Izamal, Campeche, Peto, Ticul y Valladolid (Quezada, 2010). Otro desarrollo urbano importante fue la inauguración del primer tranvía de la ciudad de Mérida, el cual es instalado en 1881 y a los pocos años viajaba al cercano pueblo de Itzimná, donde en 1893 la empresa de tranvías instala un centro de diversiones llamado "Los Recreos de Itzimná" (Cervera, 2007).

Esta expansión de las comunicaciones y transportes sin precedentes en la región y el país, darían como resultado no solo el intercambio de bienes y recursos, sino también de arte y cultura, pues estas vías de comunicación serían ampliamente usadas por las compañías de bufos y zarzuelas yucatecas, mexicanas, cubanas y europeas.

La industria henequenera no solo permitió el crecimiento de las comunicaciones al interior de la península, sino además que los tratos comerciales de la oligarquía local permitieron que las rutas de intercambio internacional llegaran directamente a la región, sin la necesidad de depender de la ciudad de México u otro punto de la República. Por supuesto que este gran acercamiento económico hacia agentes extranjeros también fue un vehículo para promover la cultura externa a la península dentro del gusto de la burguesía yucateca.

La demanda del público "culto" meridano por la literatura europea y estadounidense era bien surtida por casas distribuidoras establecidas en la ciudad, las cuales se valían del comercio de los barcos de vapor para importar directamente del lugar de origen las publicaciones extranjeras; tan solicitadas dentro de los círculos aristocráticos meridanos, pues como lo señala Quezada (2010): “... Se contaba con dos casas importadoras de libros y revistas europeas y estadounidenses. Los vapores traían obras a las pocas semanas de ser publicadas por las imprentas más importantes de Barcelona, París o Nueva York" (p. 177).

Esta gran conexión comercial y cultural peninsular con agentes europeos y estadounidenses tuvo un fuerte impacto en el gusto peninsular, ya que el interés por las corrientes literarias más de moda de la época, el romanticismo europeo y el incipiente modernismo, irían desarrollando una escuela poética regional, de donde emergerían autores de la talla de José Peón Contreras o Luis Rosado Vega.

Esta aproximación de la burguesía urbana meridana a las corrientes literarias se logró mezclar de manera bastante natural con las influencias musicales importadas de la isla de Cuba, creando un híbrido bastante peculiar entre lo "popular cubano" y lo "culto europeo".

Poco a poco, la poesía en Yucatán comenzaba a compartir su musicalización de barcarolas o valses con habaneras y guarachas. Sobre esta etapa, refiriéndonos, por supuesto, a la música desarrollada principalmente en el interior de los salones de las casas acomodadas meridanas, Martínez (2014) nos dice: “... Esta primera época de la canción yucateca podría considerarse una etapa aristocrática, debido a que la mayor parte de sus autores y compositores creaban sus producciones para ser cantadas en las fiestas de las familias pudientes de Mérida..." (p. 39).

Esta gran demanda aristocrática por música y diversión, provocó que tanto los músicos profesionales y diletantes como los poetas, muchos de los cuales también pertenecían a los grupos aristocráticos de la península, buscaran recrear y presentar en su trabajo el tan solicitado "exotismo" que demandaban las familias acomodadas.

La gran influencia de los conjuntos de operetas y bufos provenientes de Cuba (la cual venía acrecentándose desde mediados del siglo xIx) (Vega, 2010), empieza a reflejarse en sus composiciones; se comienzan a escuchar guarachas, habaneras y danzas de clara influencia cubana dentro de la producción musical yucateca.

Por lo visto líneas arriba, los compositores yucatecos activos hacia el periodo que comprende de 1880 a 1920 estaban más vinculados con los estilos y tradiciones caribeñas que con el resto de la república mexicana. Compositores como Fermín Pastrana, Antonio Hoil, Marcial Cervera Buenfil, Alfredo 
Evidencias de la recepción del bambuco colombiano en Yucatán

(1908-1920)
MÚSICA, CULTURA Y PENSAMIENTO • NOVIEMBRE 2019

VOL. VIII(8) |63-80. ISSN- 2145-4728; ISSN-E 2665-2382
Tamayo y Cirilo Baqueiro Preve Chan Cil -El pequeño Cirilo- (Vega, 2007), entre otros, lograron plasmar de una manera muy original la influencia cubana en su producción musical. La canción yucateca, por tanto, estaba empezando a consolidarse con esta generación de músicos.

El principal campo de acción de los músicos locales, además del de las tertulias y los salones, será el de los escenarios de los teatros de zarzuela (Martínez, 2014), donde se mezclarían con las danzas y canciones cubanas llevadas a la península por las compañías de bufos cubanos y de zarzuela. En la ciudad de Mérida, estas compañías cubanas se presentaban en el Circo Orrín, el Teatro Peón Contreras y el Circo-Teatro Yucateco $^{7}$ (Perea, 2014), en este último solían alternar funciones con corridas de toros, obras teatrales, y exhibiciones cinematográficas (Cervera, 2007).

Las compañías zarzueleras y de bufos, tanto locales como extranjeras, competían entre sí por el gusto yucateco. Las puestas en escena, en su mayoría de índole cómica, comienzan a utilizar temáticas locales, tal es el caso de las comedias Mérida al vuelo ${ }^{8}$ o Mérida en carnaval (Flores y Dueñas, 2010). Del mismo modo, el presentar escenas o actos novedosos podía ser un mecanismo crucial al momento de atraer públicos a las carpas y teatros; géneros que se estaban desarrollando en Cuba eran rápidamente presentados en las ciudades de la península: la guaracha, el danzón, la criolla, el bolero y la habanera comienzan a alternarse con canciones y jaranas yucatecas.

Quizá, y en vista de la rápida asimilación que los yucatecos hacían de los géneros cubanos, no es difícil suponer que lo mismo sucedería con los ritmos andinos llevados a la península por el dueto de Pelón y Marín y que, géneros como el bambuco, no solo fueran reproducidos y asimilados, sino también readaptados al gusto meridano. Sin duda, también es importante señalar que la influencia colombiana no llegó directamente de Sudamérica, sino que, recordando lo que apareció líneas arriba, vino de Cuba,

\footnotetext{
7 El Circo-Teatro Yucateco abre sus puertas el 17 de junio de 1900 con un evento taurino. El inmueble contaba con espacio para 3500 espectadores y fue demolido en 1961.

8 De la cual formó parte la famosa guaracha La mestiza con música de Cirilo Baqueiro Chan Cil. La mestiza, guaracha yucateca de la revista inédita titulada Mérida al vuelo, música de Chan Cil (ca. 1895). La Gaceta Musical. Ed. Arturo Cosgaya, número de prensa 2. Fondo Gerónimo Baqueiro Foster (FGBF) - Centro Nacional de Investigación y Documentación Musical "Carlos Chávez" (Cenidim), Mérida, México.
}

lo que considero, fue un factor importante para la aceptación del bambuco en Yucatán.

Ahora que se presentó un panorama muy grosso modo del estado cultural y económico de la región yucateca a la llegada del dueto colombiano, es momento de analizar la gira del dueto como tal y cuál fue su impronta en la vida musical yucateca. Lo que nos permitirá ver las repercusiones de la primera grabación colombiana en la cultura local; la cual, después de la influencia colombiana, no volverá a ser la misma.

\section{La gira en Mérida, la grabación y la edición}

Como se pudo apreciar líneas arriba, no existe debate al momento de señalar al dueto de Pelón y Marín como los introductores de los ritmos andinos colombianos en la región de Yucatán a principios del siglo $x^{9}$. Sin embargo, parecería que la intención del dúo estaba lejos de fundar una escuela de música colombiana en México y más cercana a poder subsanar las penurias económicas sufridas en Cuba, además de lograr acercarse a las casas discográficas, radicadas en los Estados Unidos y México.

Este periplo hacia la tan ansiada fama discográfica tuvo su gran primicia para Pelón y Marín en Panamá, región donde en 1907, y llevados por el éxito obtenido, los músicos deciden fundar una sastrería (García, 2009). Posteriormente, continúan su gira por el área insular del Caribe; islas como Jamaica y Cuba serían testigos de las presentaciones del dueto; sin embargo, es en Cuba donde ocurre el punto de quiebre. Al parecer no son tan bien recibidos como esperaban y pasan dificultades económicas.

El bambuco no fue tan impactante para el oído cubano como se hubiese deseado ${ }^{10}$. Es probable que en este momento pudo haber surgido para el dueto la disyuntiva de regresar como se pudiese a Colombia o jugarse la suerte con un último intento en la gira.

Se deciden por la segunda y emprenden su viaje a México. En la ciudad de La Habana toman otra decisión importante: esta vez deciden no viajar solos,

9 Las evidencias materiales encontradas así lo demuestran, aunque, como sabemos, siempre hay que estar abiertos a nuevos hallazgos.

10 Aunque cabe señalar que compositores e intérpretes cubanos como María Teresa Vera o Rosendo Ruiz adoptaron y cultivaron el género en su producción musical. 
sino que, como ya se dijo, viajan dentro de la compañía de variedades de Raúl del Monte (Azula et al., 2011). Quizá ya estaban enterados de la gran acogida que tenían estas compañías antillanas en las ciudades de la península yucateca.

Es así como Raúl del Monte y su compañía llegan a Yucatán en 1908 y es justo que durante este viaje (siendo probable que fuese antes de llegar a tierra) el dueto de Pelón y Marín, ahora dentro de la nómina de Del Monte, cambian su nombre a "Los Trovadores Colombianos" (Azula et al., 2011). Esto quizá como un ardid publicitario, pues automáticamente hacía que esta compañía cubana y no otra, presentase al público yucateco un espectáculo traído desde la lejana Sudamérica: un par de trovadores que interpretaban poemas románticos en ritmos exóticos para los oídos peninsulares, ya habituados a las tradicionales guarachas cubanas o los danzones.

Esta nueva y audaz propuesta musical -pues ciertamente no había ninguna certeza de que la suerte del dueto sería distinta a la mala experiencia vivida en Cuba- tiene su gran debut en nada más y nada menos que en el Circo-Teatro Yucateco, el día viernes 24 de julio de ese mismo año (Pérez, 2010). El triunfo es apabullante, las canciones andinas colombianas consiguen con el público yucateco lo que no pudieron en la isla cubana, un éxito total; incluso, se recuerda la llegada de Pelón y Marín con mucho cariño en la ciudad de Mérida; pues, como lo señala Martínez (2014):

En julio de 1908 arribaron a la ciudad de Mérida dos extraordinarios bohemios colombianos. Pedro León Franco y José Adolfo Marín, popularmente conocidos como Pelón y Marín, sin más caudal que una alegría inagotable y la guitarra bajo el brazo, quienes impactaron la imaginación musical de los peninsulares. Su estancia no duró más de diez días (p. 47).

Parece que en esos diez días en Mérida todo fue aciertos y buena fortuna para el dúo de trovadores colombianos; pues, precisamente, para septiembre de ese año de 1908 son invitados a grabar por el sello discográfico Columbia (el cual tenía una sucursal en la ciudad de México). En las sesiones de grabación se lograron registrar 40 temas, por los cuales, Pelón y Marín percibieron una paga de 400 dólares, suma bastante generosa para la época (García, 2009).

Una posible razón por la cual este dueto colombiano tuvo una gran acogida dentro del público yucateco fue, quizá, la relación que existía entre las prácticas populares de la canción a dos voces en ambos países, pues desde mediados del siglo xıx, había un desarrollo simultáneo de este estilo de canto con acompañamiento de guitarra en varios países latinoamericanos ${ }^{11}$, así como una exacerbada exploración de los cánones y gusto estéticos de la literatura romántica. Sobre ello, Azula et al. (2011) señalan:

[...] [l]a tradición de la trova que empezó en el oriente de Cuba, tuvo un desarrollo paralelo en varios países de América Latina, incluyendo a Puerto Rico, Colombia y México. Las serenatas musicales estaban de moda y el estilo de cantar a dueto con acompañamiento rítmico de guitarra, evolucionó como un verdadero arte popular (pp. 43-44).

Hablando concretamente del trabajo de grabación, existe un consenso en nombrar al bambuco Simón el enterrador o simplemente $E$ l enterrador como la primera canción en ser grabada de esta serie de 40 temas; autores como Portaccio (1995), García (2009) o Azula et al. (2011) sostienen esta postura.

Sin embargo, Ramírez-Casas (2017) señala que el lugar de la primera grabación colombiana no la ocupa $E l$ enterrador, sino una musicalización a ritmo de bambuco del poema La brisa del poeta mexicano Manuel Acuña Ramírez. No obstante, y aunque así lo fuese, parece que la musicalización del poema de Manuel Acuña no tuvo la gran acogida o el impacto posterior que sí tuvo El enterrador.

De lo expuesto anteriormente, la suerte favoreció a Pelón y Marín, y a la música colombiana en Yucatán durante su estadía en México, pues la estancia del dueto va a coincidir con la inquietud de poetas y músicos locales de consolidar un corpus de canciones - un canon musical yucateco, si se quiere- que fueran un referente musical de la época en la península $^{12}$. Esta inquietud se ve materializada en el famoso Cancionero, también conocido como Cancionero de Chan Cil, del poeta Luis Rosado Vega y el pianista

11 Es importante recalcar que, aunque sí existían tradiciones compartidas entre varias regiones latinoamericanas, las diferencias en la instrumentación, por ejemplo, irán formando estéticas interpretativas distintas. En Yucatán se favorece el uso del requinto, mientras que la práctica del tiple al gusto colombiano, es desconocida.

12 Con esto no quiero decir que no hayan existido publicaciones o ediciones de partituras de canciones y compositores locales, al contrario, desde mediados del siglo xix ya existían publicaciones de música en Yucatán. Un ejemplo de las revistas decimonónicas locales de este tipo es la ya mencionada Gaceta musical. 
Evidencias de la recepción del bambuco colombiano en Yucatán (1908-1920)
MÚSICA, CULTURA Y PENSAMIENTO • NOVIEMBRE 2019

VOL. VIII(8) |63-80. ISSN- 2145-4728; ISSN-E 2665-2382
Filiberto Romero, los cuales en 1909 reúnen una selección de temas de compositores locales y extranjeros de moda en la península. Sobre este cancionero, el maestro Vega (2007) señala:

[...] destaca, [ ], el editado un año antes del inicio de la Revolución mexicana y conocido en nuestros días como "de Chan Cil". Esta colección incluye composiciones de trovadores de la región, además de canciones cubanas y colombianas, transcritas para dos voces con acompañamiento pianístico (pp. 51-52).

Como puede apreciarse, en el Cancionero aparecen temas colombianos, que no son otra cosa más que las transcripciones de las grabaciones realizadas por Pelón y Marín para el sello Columbia un año antes.

En solo un año, los géneros andinos lograron impactar de tal manera al gusto popular yucateco, que Luis Rosado Vega y Filiberto Romero decidieron incluir temas colombianos en su Cancionero. El cual era, precisamente, un reflejo del gusto musical local: guarachas, bambucos, canciones, valses, barcarolas, danzas y demás géneros desfilan en las páginas producidas por la Imprenta Gamboa Guzmán, de Rosado Vega, como las grandes protagonistas de las noches de diversión de las casas y las familias meridanas de principios del siglo xx (véase figura 3).

De los cuarenta temas grabados por "Los Trovadores Colombianos", los editores del Cancionero seleccionaron cuatro canciones: tres bambucos (Ya ves, Asómate a la ventana y Poema del nido) (véanse figuras 4 y 5) y un pasillo (Despedida colombiana). Con esto se demuestra también que el bambuco fue más apreciado por el público yucateco que el pasillo ${ }^{13}$, y que, a la larga, lo terminaría desplazando totalmente en la península.

No obstante, cabe señalar que existieron grandes problemas al momento de transcribir los géneros musicales colombianos, pues los editores presentan un producto final en compás de 2/4, algo bastante diferente de los compases habituales de un bambuco colombiano (6/8 o 3/4). Esto puede deberse, quizá, a la incipiente industria fonográfica del momento y a la mala calidad de las grabaciones. Sobre esta cuestión, el maestro Vega (2007) señala:

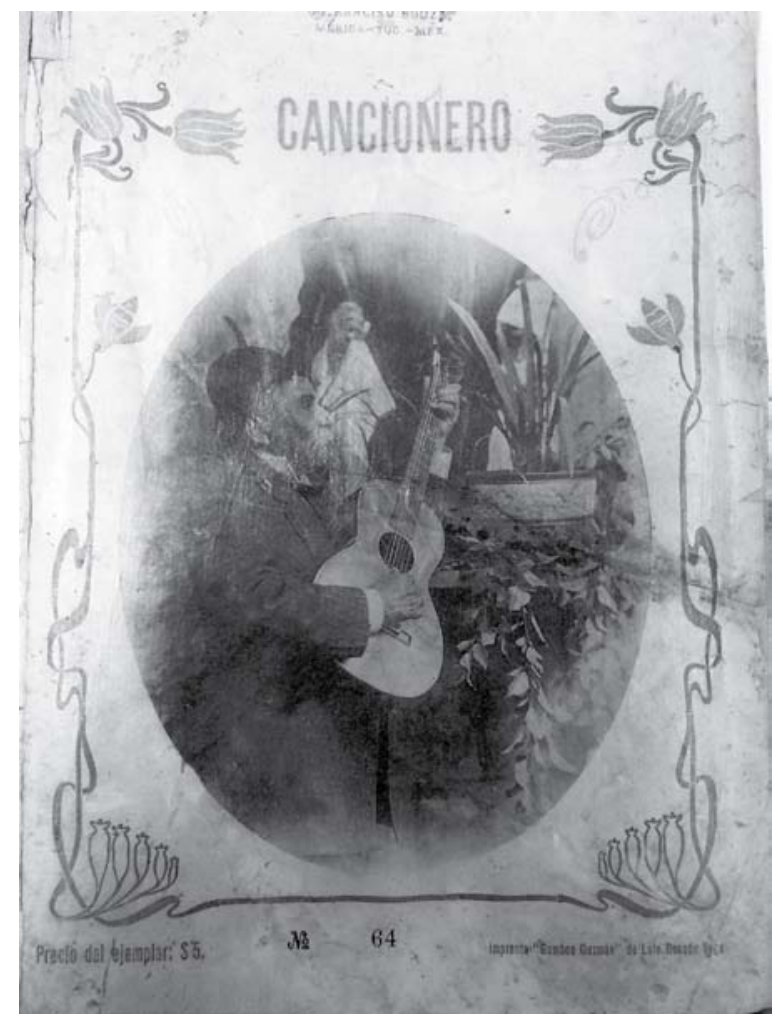

Figura 3. Portada de un ejemplar del Cancionero de Chan Cil conservado en el Fondo Gerónimo Baquiero Foster del Cenidim en la ciudad de Mérida, Yucatán.

Fuente: fotografía del autor ${ }^{14}$.

Al año siguiente de las grabaciones históricas que Pedro León Franco y Adolfo Marín (Pelón y Marín) realizan para la Columbia en la ciudad de México, se publican en el Cancionero cuatro de los títulos que el dueto colombiano registra en discos de pizarra. Las canciones elegidas para la edición de Rosado Vega son los bambucos Asómate a la ventana [...], Ya ves y Poema del nido, además del pasillo Despedida colombiana. [...]. Si asumimos que las canciones colombianas publicadas en el Cancionero fueron transcritas a partir de los discos de 78 r.p.m., son comprensibles, entonces, los problemas que se enfrentaron los realizadores del libro ante un género polirrítmico como el bambuco, dadas la pobreza sonora de las grabaciones o la ausencia de un instrumento que ejecutara las figuras del bajo. El punto es que, al no identificar la presencia simultánea de compases en $6 / 8$ y $3 / 4-0$, en todo caso, solo la del compás de 6/8-, Romero escribe los bambucos en 2/4 (p. 57). 


\section{BAMBUCO COLOMBIANO.}
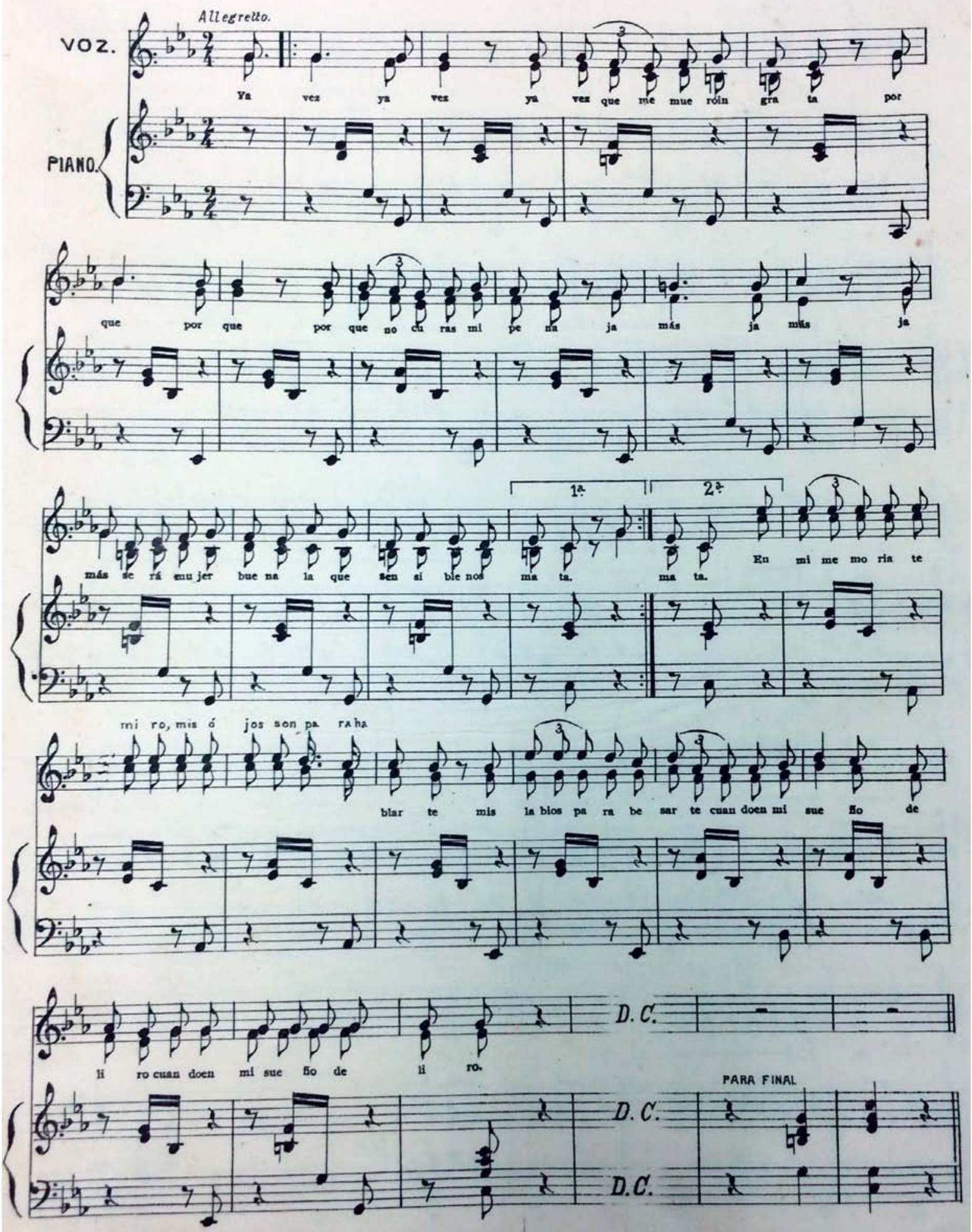

Figura 4. Música del bambuco Ya ves, aunque, en este caso, aparece con el título de Bambuco colombiano. Pieza conservada en el Fondo Gerónimo Baquiero Foster del Cenidim en la ciudad de Mérida, Yucatán. 
Evidencias de la recepción del bambuco colombiano en Yucatán (1908-1920)
MÚSICA, CULTURA Y PENSAMIENTO • NOVIEMBRE 2019

VOL. VIII(8)|63-80. ISSN- 2145-4728; ISSN-E 2665-2382

\section{Bamburec colombiam(1)}

Ya vez, que me muero ingrata, porque no curas mi pena. Jamás será mujer buena la que insensible nos mata.

En mi memoria te miro, mis ojos son para hablarte, mis labios para besarte, cuando en mis sueños deliro.

Yo quiero que tu alma pura si es que tienes corazón, se incendie con la pasión que en mi pupila fulgura.

Esa insoportable calma te arrancara con dolor, porque la falta de amor produce anemia en el alma.

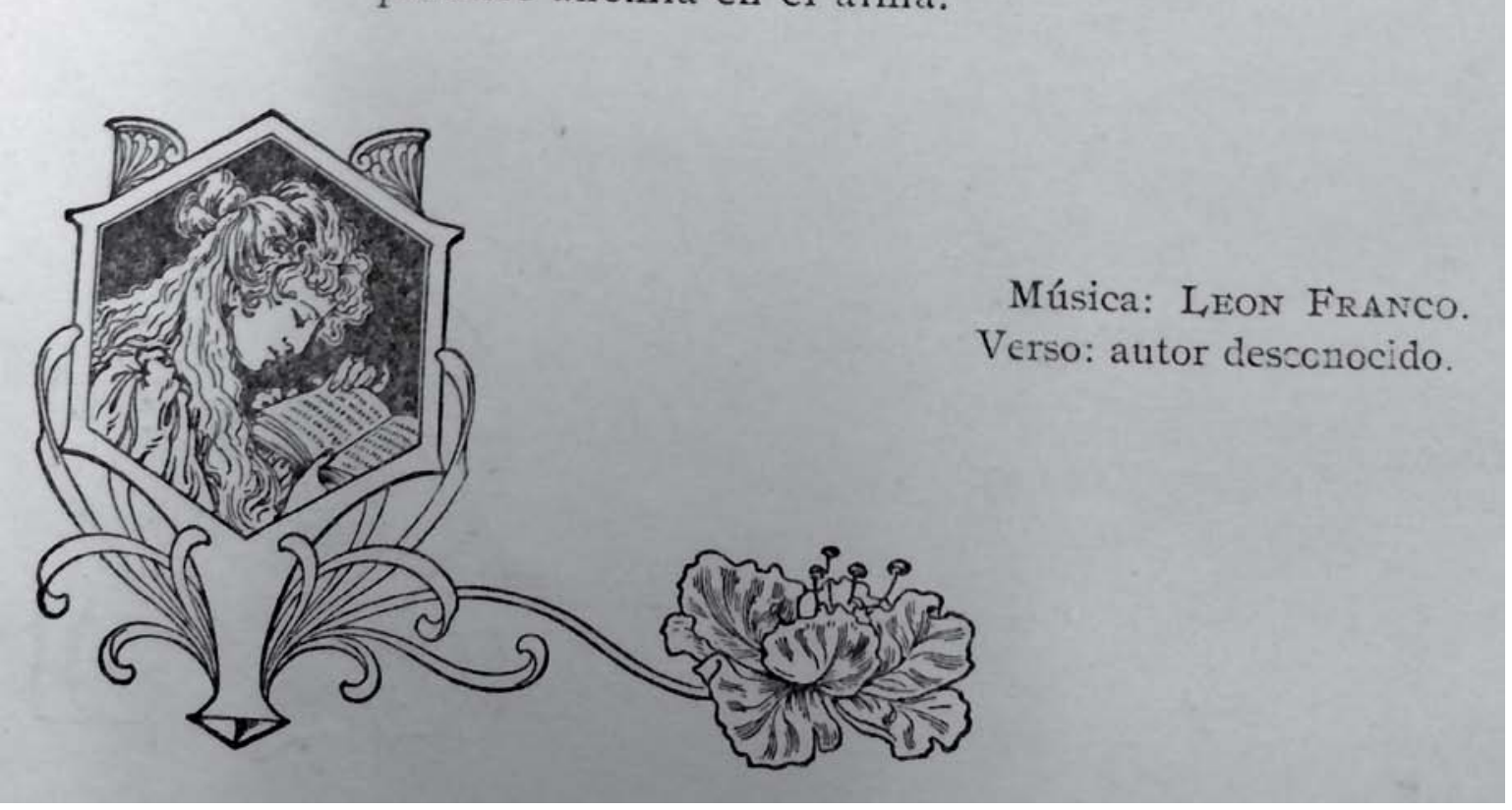

Figura 5. Transcripción de la letra del bambuco Ya ves. Aunque en esta edición se le adjudique la música a León Franco y la letra a un autor desconocido, se sabe que ambas son autoría de Pedro Morales Pino. Pieza conservada en el Fondo Gerónimo Baquiero Foster del Cenidim en la ciudad de Mérida, Yucatán.

Fuente: fotografía del autor ${ }^{16}$. 
Con este sacrificado pero afortunado dueto de músicos-sastres se inaugura la vida musical grabada en Colombia y también podemos comenzar a hablar de evidencias materiales de los géneros musicales colombianos en Yucatán.

A partir de este momento, la vida musical colombiana comienza a visibilizarse para las grandes compañías discográficas, y por tanto, un nuevo nicho comercial estaba naciendo, del cual se beneficiarían directamente las casas fonográficas estadounidenses, los músicos colombianos y, curiosamente, también los músicos yucatecos; pues el impacto que dejaron Pelón y Marín en la península sería retomado diez años después por otro dueto colombiano, formado por los bogotanos Wills y Escobar: "Los Reyes del Bambuco" quienes lograran consolidar el gusto por el género en la península de Yucatán, desencadenando el inicio de la tradición del bambuco a la yucateca.

\section{"Los Reyes del Bambuco" y Ricardo Palmerín}

Gracias a las grabaciones pioneras de Pelón y Marín, la música andina colombiana comienza a visibilizarse y ocurrirá un fenómeno bastante interesante en la historia de la música colombiana. Las giras se generalizan y las grabaciones en ciudades estadounidenses (en particular, Nueva York) no se hacen esperar. Las casas más importantes del momento, como la RCA Víctor, la Columbia o la Brunswick, comienzan a contratar músicos colombianos en sus salones de grabación (Londoño, 2015).

Duetos como el de Wills y Escobar o las giras y grabaciones de Jorge Áñez, comenzarán a consolidar una visión estética de la música colombiana; del sonido “nacional" desde el extranjero (L. León, comunicación personal, 19 de septiembre de 2017), lo cual no era otra cosa que los repertorios de géneros andinos (bambucos, pasillos, danzas, etc.). Es interesante hacer notar que la gran influencia fonográfica-musical colombiana de principios del siglo xx, desarrollada por sus mismos músicos, se fraguó fuera de su país de origen para luego ser importada al mismo.

Este gran dinamismo en la vida musical de los conjuntos andinos colombianos tuvo repercusiones importantes en la península yucateca. Por un lado, la impronta dejada por "Los Trovadores Colombianos" en la vida musical de Yucatán se encontraba materializada no solo en una producción fonográfica, sino también plasmada en forma impresa dentro del Cancionero de Luis Rosado Vega y Filiberto Romero. Por otro, la ubicación geográfica de Yucatán seguía siendo una estación de paso estratégica entre las rutas comerciales y artísticas que conectaban el Caribe con el resto de América.

Es probable que esta situación geográfica, aunada a la buena aceptación que se tenía en la península de géneros como el bambuco y el pasillo fueron las razones que atrajeron en 1919 a uno de los duetos más célebres de la historia de la música andina colombiana a realizar una estancia breve en Mérida, me refiero al ya mencionado dueto de Wills y Escobar.

Sobre la brillante carrera de este dueto, considerado por muchos como el mejor dueto colombiano de su época y el que profesionalizó el género, María del Pilar Azula apunta que Alejandro Wills tenía contacto con Alberto Escobar desde 1903, aunque fue en 1914 cuando decidieron crear un dueto para competir con Patiño y Forero por una grabación para el sello Columbia (Azula et al., 2011). Después de esto, su labor se repartió entre giras, y grabaciones por prácticamente toda América (Azula et al., 2011). Sobre su estadía en Nueva York, Pérez (2010) señala:

El 7 de abril de 1919, llegan a Nueva York procedentes de La Habana; los acompaña el violinista Miguel Bocanegra, con quien integran el Trío Colombiano. En esta ciudad, el Trío realiza 30 registros fonográficos en el sello Camden, con obras de autores y géneros colombianos, a excepción de dos danzones cubanos y el joropo Alma llanera. Allí permanecen durante cuatro meses $^{17}$ (pp. 445-446).

Posteriormente a estas afortunadas grabaciones en Nueva York, el dueto regresa a Colombia, no sin antes detenerse unos meses en la península yucateca para probar suerte en sus escenarios.

La estadía del dúo en la ciudad de Mérida fue del 20 de agosto al 21 de octubre de 1919. Sin embargo, y a pesar de estos escasos dos meses de estancia, su recepción y acogida fue tremenda. Su presentación

17Cabe señalar que en estas grabaciones aparece un bambuco Ilamado Frijolito, que no es otra cosa más que el son jalisciense de El frijolito, grabado entre 1908 y 1909 por el Cuarteto Coculense en la ciudad de México para los sellos Columbia, Edison y Víctor (Dordelly, 2004, xv, 23). La primera cuarteta es prácticamente igual en las versiones de Wills y Escobar y la del Cuarteto Coculense; la melodía es la misma. 
Evidencias de la recepción del bambuco colombiano en Yucatán

(1908-1920)
MÚSICA, CULTURA Y PENSAMIENTO • NOVIEMBRE 2019

VOL. VIII(8) |63-80. ISSN- 2145-4728; ISSN-E 2665-2382 oficial es patrocinada por la Asociación de Periodistas de Yucatán para llevarse a cabo en el Ateneo Peninsular (Pérez, 2010). El jueves 21 se presentan dentro de la empresa de variedades de Manuel Ocampo, la cual realizaba la variedad de tres funciones diarias de la Compañía de Zarzuela Yucateca, presentada en el Teatro Olimpia, es en estas presentaciones que se les comienza a Ilamar "Los Reyes del Bambuco" (Pérez, 2010).

Entre agosto y septiembre son contratados por el Teatro Apolo para actuar por siete noches, al final de la proyección cinematográfica (Pérez, 2010). En su despedida de la ciudad el 21 de octubre, se ofrece una velada a su beneficio donde se presentan el cuarteto de violonchelos de Manuel Caseres [sic], Alfredo Tamayo, Alonso Patrón y Francisco Blum, y el Orfeón Palmerín integrado por Manuel Ruiz, Anselmo Castillo, José Cervera, Ernesto Ortiz, Enrique Galaz, Agesilas Marín, Florencio Cano y el propio Ricardo Palmerín (Pérez, 2010). Sobre la estadía de este dueto en Mérida, Martínez (2014) señala:

[...] Alejandro Wills y Alberto Escobar, quienes lograron una temporada consagratoria en Mérida y ciudades circunvecinas, no mayor a cien días, trajeron a esta península los inspirados bambucos de su tierra nativa, e influyeron de inmediato en los compositores de las tierras mayanses.

Nuestros cancionistas de entonces, especialmente Ricardo Palmerín, Ernesto Paredes Vera y Carlos Salazar Manzanero, lo adoptaron y empezaron a componer bambucos, dándoles un acento propio afianzando la querencia del aire colombiano, el cual tomó carta de naturaleza peninsular y adquirió otra dimensión (p. 47).

De la estadía de Wills y Escobar en Mérida y las relaciones que entablaron con los músicos locales, quizá la más trascendental fue la que realizaron con el compositor, guitarrista y cantante, Ricardo Palmerín Pavía (1887-1944). De él se sabe que nació en el pueblo de Tekax, Yucatán y fue hijo de Bernabé Hernández Palmerín, quien se cree, fue un músico michoacano llegado a Yucatán en 1867 y de quien Ricardo aprendió a tocar la guitarra (Pérez, 2010); aunque otros autores señalan que su padre fue un militar de origen zacatecano (García, 2009). Ya entrado el siglo xx, comienza a ser conocido en los círculos musicales de Mérida como músico y profesor de guitarra de las familias acomodadas de la ciudad (Pérez, 2010).
La relación que entablaría con Wills y Escobar al momento de la despedida de estos de Mérida, provoca que Palmerín aprenda de primera mano el género del bambuco y, al parecer, comience a experimentar con él, al grado de que al año siguiente del contacto con el dúo colombiano presenta su propio bambuco, titulado El rosal enfermo con letra del poeta Lázaro Sánchez Pinto (Pérez, 2010).

A partir de este momento, se crea un parteaguas indiscutible en la vida musical yucateca, pues gracias al aporte de Palmerín se comenzará a consolidar una escuela bambuquera en Yucatán. Sobre la relación de Palmerín y el bambuco, García (2009) señala que

[...] fue uno de los primeros en cultivar este género con gran acierto a grado tal que aún se siguen interpretando la mayor parte de sus bambucos. [...] "Flores aladas", "Semejanzas", "Que entierren mi cuerpo", "Novia envidiada", "Neblina", "El crucifijo", "Las dos rosas", etc. Todos de la autoría de Ricardo Palmerín.

Lo que no podemos negar, es la importante relación que tuvo la transmisión del bambuco a través de la oralidad, pues la relación directa de músicos yucatecos y colombianos permitió el aprendizaje del género, lo que parece demostrar el desplazamiento del Cancionero de 1909 como herramienta pedagógica para el aprendizaje de los géneros colombianos entre los músicos de la península.

No obstante, aunque fue directamente de un dueto colombiano de quien Palmerín aprendió el género, podemos apreciar en la partitura de El rosal enfermo diferencias sustanciales, las cuales crearán una brecha en ciertas particularidades rítmicas entre los bambucos colombianos y los yucatecos.

El ejemplo más claro lo tenemos en el movimiento del bajo de la mano izquierda del acompañamiento del piano, el cual utiliza las figuras rítmicas de silencio de corchea-corchea-negra-negra, que difiere con el acompañamiento tradicional del bajo en un bambuco, el cual corresponde a silencio de negra-negra-negra (véanse figuras 6a, 6b y 7).

Con esto no quiero decir que el acompañamiento usado por Palmerín sea totalmente ajeno al uso colombiano, la diferencia radica en que los yucatecos usan esta célula rítmica como una constante $y$, por tanto, es el elemento central de sus bambucos; mientras que en Colombia, este particular movimiento 


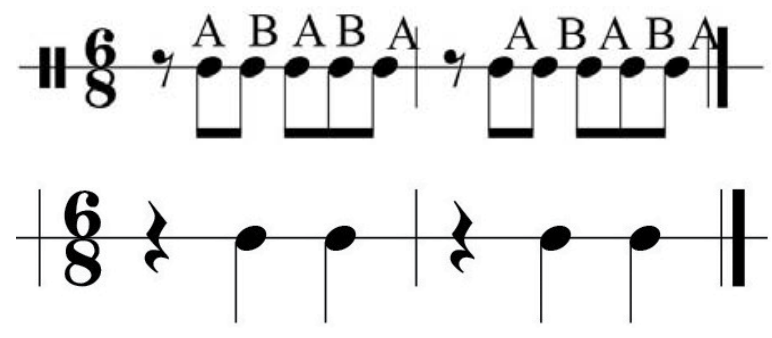

Figuras $6 \mathrm{a}$ y $6 \mathrm{~b}$. Patrones rítmicos básicos en 6/8 del acompañamiento (izq.) y del bajo (der.) para un bambuco colombiano. Fuente: el autor.

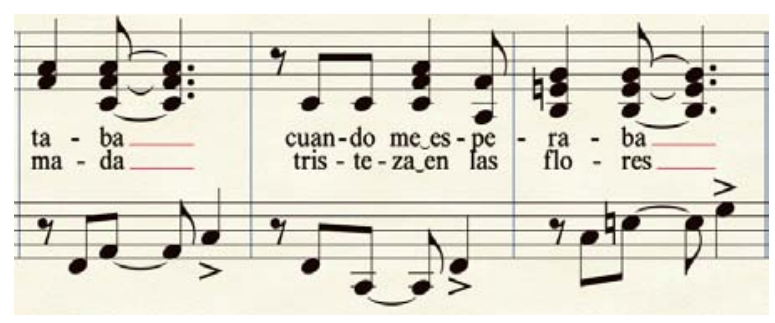

Figura 7. Ejemplo de variante rítmica del acompañamiento del bambuco El rosal enfermo de Ricardo Palmerín (compases 9 al 11) (Pérez y Herrera, 2012). Se puede apreciar en el bajo el uso a manera de ostinato del patrón rítmico silencio de corchea-negra-negra.

del bajo puede utilizarse de manera muy esporádica (sobre todo, utilizado por los guitarristas con el movimiento del pulgar como un gesto rítmico).

Además de las diferencias entre las células rítmicas, la temática y el uso del bambuco en Yucatán se fue diferenciando de su homólogo colombiano, pues al avanzar el siglo xx, el bambuco en Colombia comenzó a tener un uso cada vez más importante para narrar o "paisajes" o escenas algunas veces idealizados de la vida rural colombiana, sobre todo andina (G. Pérez, comunicación personal, 28 de agosto de 2017); mientras que el bambuco yucateco se asimiló a los repertorios de la naciente trova yucateca y tuvo un uso amoroso y de cortejo como los otros dos géneros importantes de la península: el bolero y la clave.

Con estas diferencias pequeñas pero sustanciales, el bambuco en Yucatán y en Colombia comenzará a tomar caminos distintos, aunque como lo podemos ver, nunca del todo ajenos (véase figura 8).

\section{Conclusiones}

Las evidencias presentadas en este trabajo nos ponen frente a un fenómeno de intercambio musical que puede dividirse en dos vertientes que al final se entreveran. Una de ellas es el desarrollo de nuevos patrones rítmicos dentro de la edición de partituras $y$, la otra, el nacimiento de una novel tradición musical que parte directamente de la oralidad, siendo $E I$ rosal enfermo de Ricardo Palmerín el primer producto de esta presencia colombiana dentro de la producción de los compositores yucatecos.

A partir de la presentación de El rosal enfermo de Palmerín, la vida musical yucateca cambió para la posteridad. En primer lugar, se inició el camino de la tradición del bambuco yucateco, el cual ayudaría a configurar la naciente "trova yucateca" como la conocemos hoy en día. En segundo lugar, la labor tanto de Pelón y Marín como de Wills y Escobar logró superar los posibles fines inmediatos de ambos duetos: dar a conocer su trabajo mediante giras y grabaciones y la consiguiente fama y estabilidad económica que esto pudiera brindarles.

Con esto quiero decir que, aunque el bambuco fue llevado por todo el continente americano, no solo por estos duetos, sino también por la Lira Colombiana, La Lira Antiqueña, Jorge Áñez y demás artistas activos entre la última década del siglo xix y las primeras de $x x$, fue en Yucatán donde se logró arraigar de tal modo que comenzó a desarrollar una tradición musical con valores estéticos propios, que aunque el género sigue siendo nombrado bambuco, para un yucateco o un colombiano tiene ciertas diferencias que parecerían ser ineludibles.

Un ejemplo claro es el del acompañamiento, en el cual podemos ver diferencias importantes en el uso de patrones rítmicos reiterativos en los bambucos yucatecos. Es probable que dicho patrón (silencio de corchea-corchea-negra-negra) se deba a una adaptación y síntesis de los patrones rítmicos colombianos básicos del bajo y del acompañamiento en uno solo.

Para esto, la oralidad fue un elemento fundamental. Es muy probable que otros músicos, además de Filiberto Romero, pudieron aprender de las grabaciones de Pelón y Marín al transcribirlas y también, probablemente, pudieron lograr asimilar el compás de $6 / 8$ o 3/4 de las grabaciones (aunque estas nociones sean por el momento hipótesis).

Sin embargo, lo que sí está claro es que la manera directa de aprender el bambuco de Ricardo Palmerín con Wills y Escobar, fue la clave para que los músicos locales desestimaran de manera contundente los patrones rítmicos editados dentro del Cancionero 
Evidencias de la recepción del bambuco colombiano en Yucatán (1908-1920)
MÚSICA, CULTURA Y PENSAMIENTO • NOVIEMBRE 2019

VOL. VIII(8) |63-80. ISSN- 2145-4728; ISSN-E 2665-2382

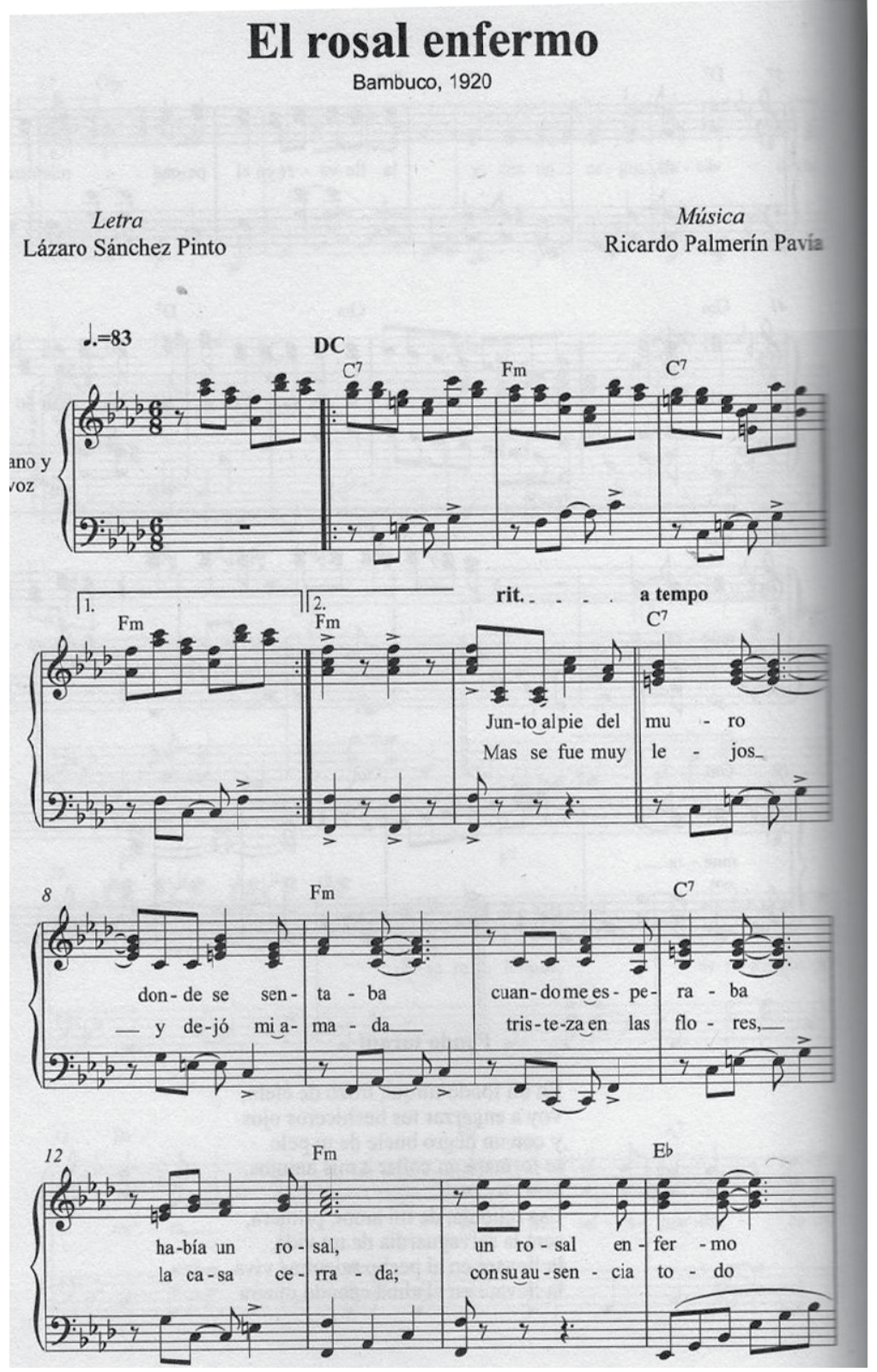

Figura 8. Introducción y primeros compases de El rosal enfermo, donde se demuestra claramente el patrón de acompañamiento de un bambuco yucateco en la mano izquierda del piano (Pérez y Herrera, 2012).

de 1909, los cuales, como se pudo apreciar, están escritos en compás de $2 / 4$.

Otra brecha indiscutible entre los bambucos colombianos y los yucatecos se comenzará a notar en el uso del género: mientras que para los autores colombianos de principios del siglo pasado, el bambuco se convirtió en el vehículo ideal de las visiones costumbristas y "tradicionales" del pueblo colombiano, así como también las temáticas amorosas y pueblerinas (como los bambucos: Campesina santandereana, El corazón de la caña o Altiva samaritana), en Yucatán se utilizó casi, exclusivamente, para una función de cortejo, de temática amorosa o haciendo alusión al objeto amado (Semejanzas, Nuestro nido, En tus ojos). Aunque existen contados casos donde es utilizado del mismo modo que en Colombia, esto es para describir costumbres, escenas o personajes "típicos" o "propios" de Yucatán (como el bambuco Mestiza).

Igualmente, la instrumentación implicaría cambios sustanciales entre uno y otro bambuco. Mientras que en Colombia el uso del tiple combinado con el de la guitarra es fundamental, en Yucatán, al no existir el instrumento, no se le necesita, y la instrumentación está destinada a la guitarra y un requinto, o si se trata de un trío yucateco, es a dos guitarras y requinto. 
La historia del bambuco en Yucatán es una historia de hermandad de dos pueblos a través de una de las expresiones más bellas de todo el género humano, la música. Y es también una historia que, después del primer contacto del que se tenga un testimonio material en 1908, ha vinculado a ambos territorios desde entonces, para bien o para mal para la posteridad - más para bien, creo yo.

\section{Referencias}

Azula, M., Rodríguez, M. y León, L. (2011). Canción andina colombiana en duetos. Transcripción y aproximación documental. Bogotá: Universidad de los Andes, Facultad de Artes y Humanidades, Departamento de Música. Ediciones Uniandes, 30-48.

Barriga, M. (2005). Un palimpsesto indescifrable. La educación musical en Bogotá 1880-1920. El Artista, 2, 28-41.

Cervera, J. (2007). La Mérida de Chan Cil. En Vega, Á. (coord.) y Martín, E. (ed.), Chan Cil y otros precursores de la canción yucateca-Cancionero (pp. 83-96). México: Escuela Superior de Artes de Yucatán-Centro Regional de Investigación, Documentación y Difusión Musicales “Gerónimo Baqueiro Foster".

Dordelly, H. (2004). Cancionero del Cuarteto Coculense. Sones abajeños, México: Gobierno de Jalisco-Secretaría de Cultura de Jalisco-Cenidim-Conaculta.

Flores, J. y Dueñas, P. (2010). Los ritmos afrocaribeños durante el Porfiriato. En López, J. G. (corrección de textos y cuidado editorial) ... y la música se volvió mexicana. Testimonio musical de México núm. 51 (pp. 243-251). México: Cenidim-INBA-Concaulta-INAH.

García, F. (2009). Por los senderos del bambuco. Recuperado el 14/10/2017 de http://www.trovadores-yucatecos.com/Bambuco.html.

Londoño, P. (2015). La cultura. En Posada, E. (Carbó coord.-ed.), Colombia. La apertura al mundo (pp. 265-340). Madrid: Taurus-Fundación Mapfre.

Martínez, R. (2014). La magia de la canción yucateca. Noventa años de historia: 1890-1980, México: Conaculta.

Miñana, C. (1997). Los caminos del bambuco en el siglo xix. A Contratiempo, 9, 8-11.

Ocampo, J. (1990). Música y folclor de Colombia. Bogotá: Plaza y Janes Editores.
Perea, M. (2014). Hace 114 años se inauguró el "Circo Teatro Yucateco. Recuperado el 24/09/2018 de http://peninsuladeportiva.com/noticias/ hace-114-anos-inauguro-circo-teatro-yucateco-14019/.

Pérez, L. (2010). Diccionario de la Canción Popular de Yucatán. Mérida: Gobierno del estado de Yucatán, Instituto de Cultura de Yucatán, ESAYConaculta, (312) 445-446.

Pérez, L. y Herrera, P. (2012). Álbum de canciones yucatecas. Mérida: Gobierno del estado de Yucatán, Biblioteca Básica de Yucatán, 168.

Portaccio, J. (1995). Colombia y su música (vol. II). Canciones y fiestas de la región andina. Bogotá: José Portaccio Fontalvo. Apartado 23820, 88- 90.

Quezada, S. (2010). Historia breve de Yucatán. México: El Colegio de México, Fondo de Cultura Económica.

Ramírez-Casas, O. (2017). Bambuco antes y después de Pelón Santamarta. Postigo de Orcasas. Recuperado el 14/11/2017 de http://postigodeorcasas. blogspot.com.co/.

Rendón, H. (2009). De liras a cuerdas. Una historia de la música a través de las estudiantinas. Medellín, 1940-1980. Tesis de maestría. Medellín: Universidad Nacional, Departamento de Historia.

Santamaría, C. (2014). Vitrolas, rocolas y radioteatros. Hábitos de escucha de la música popular en Medellín, 1930-1950. Bogotá: Editorial Pontificia Universidad Javeriana, Banco de la República, 63-67.

Vega, Á. (2007). La canción en Yucatán a principios del siglo xx. En Vega, Á. (coord.) y Martín, E. (Ed.), Chan Cil y otros precursores de la canción yucateca-Cancionero (pp. 49-68). México: Escuela Superior de Artes de Yucatán, Centro Regional de Investigación, Documentación y Difusión Musicales "Gerónimo Baqueiro Foster".

Vega, Á. (2010). Danzas y danzones de la familia Cuevas. En López, J. G. (corrección de textos y cuidado editorial) ... y la música se volvió mexicana. Testimonio musical de México núm. 51 (pp. 252-257). México: Cenidim-INBA- Concaulta-INAH.

\section{Páginas web: videos}

Ochoa, A. [elAle Guerrero]. (2010, septiembre 27). Amparo Ochoa-Mestiza [archivo de video]. Recuperado de https://www.youtube.com/watch?$\mathrm{v}=$ BrmyqcH3x_U. 
Evidencias de la recepción del bambuco colombiano en Yucatán

(1908-1920)
MÚSICA, CULTURA Y PENSAMIENTO • NOVIEMBRE 2019

VOL. VIII(8) |63-80. ISSN- 2145-4728; ISSN-E 2665-2382
Pelón y Marín. El enterrador (1908). Disco 592, lado A. "El Enterrador". Columbia Records.

Pelón y Marín. [Clásicas colombianas]. (s.f.). Pelón y Marín: Ya ves (1908) [archivo de video]. Recuperado de https://www.youtube.com/watch?$v=A K G Y M T t J Y C M$.

Pelón y Marín. [Clásicas colombianas]. (s.f.). Pelón y Marín: La brisa (1908) [archivo de video]. Recuperado de https://www.youtube.com/watch?$\mathrm{v}=\mathrm{XXzsuWz4mXW}$.

Wills y Escobar. [Clásicas colombianas]. (s.f.). Wills y Escobar: Frijolito (1919).

\section{Entrevistas}

León Rengifo, Luis Fernando, entrevistado. En discusión con el autor. Bogotá: 19/09/2017.

Pérez, Germán Darío, entrevistado. En discusión con el autor. Bogotá: 29/08/2017.

\section{Fuentes de archivo}

Cancionero, Mérida, Imprenta Gamboa Guzmán, de Luis Rosado Vega, 1909. (Centro Regional de Investigación, Documentación y Difusión Musicales "Gerónimo Baqueiro Foster, Mérida-México). Fondo Gerónimo Baqueiro Foster (FGBF) - Centro Nacional de Investigación y Documentación Musical “Carlos Chávez” (Cenidim).
La Gaceta Musical, número de prensa 2. Edición A. Cosgaya. (Centro Regional de Investigación, Documentación y Difusión Musicales “Gerónimo Baqueiro Foster, Mérida-México). Fondo Gerónimo Baqueiro Foster (FGBF) - Centro Nacional de Investigación y Documentación $\mathrm{Mu}$ sical "Carlos Chávez" (Cenidim).

\section{Discografía}

Fernando León, Canción andina colombiana en duetos. Bogotá: Universidad de los Andes. (2015), compact disc. [-]

Orquesta de Cámara de Mérida, Música de salón de autores yucatecos del siglo xıx. Mérida: Escuela Superior de Artes de Yucatán - Centro de Investigación, Documentación y Difusión Musicales “Gerónimo Baqueiro Fóster”. (2017), compact disc. [-]

Varios artistas, La canción yucateca (vol. 1), La trova antigua. México: Conaculta-Fonca. (2003). [GB-CD6] 
Editorial

\section{Música y cultura}

La Música en México: Reflexiones sobre su historia particular The Music In México: Notes his particular history Alejandro Mercado Villalobos

25 Ecos lejanos de una disputa conceptual: El nacionalismo musical en Nariño Echoes far from a conceptual dispute: Musical Nationalism In Nariño José Menandro Bastidas España

45 Dos Órganos Históricos en Ibagué: Aportes para la contextualización de la tradición organística en Colombia Two historical musical organs in Ibagué: Contributions for the contextualization of the organist tradition in Colombia Nicolás Forero Molano, Mayerlín Alejandra Gómez Guzmán, Julián David Perdomo Rodríguez

63 Evidencias de la recepción del bambuco colombiano en Yucatán. (1908-1920)

Evidences of the colombian bambuco reception in Yucatán (1908-1920)

Claudio Ramírez Uribe

\section{Música y pensamiento}

81

La composición de los Tres Ballets Criollos de Guillermo Uribe Holguín como producto de exportación colombiano para un escenario panamericano

The creation of the Tres Ballets Criollos by Guillermo Uribe Holguín as a Colombian national export product for a

Pan-American scenario

Camilo Vaughan Jurado

93

Métodos y textos adoptados para la enseñanza de música de 1880- 1920 Métodos utilizados en educación informal y métodos para enseñanza de canto en las escuelas

Texts and methods used for music teaching from 1880 to 1920: Methods used in informal education and methods for singing teaching at schools Martha Lucía Barriga

\section{Música, Educación Musical y Género}

104

Identidad, yuxtaposición y resistencia:

tres categorías para entender la música

latinoamericana para piano a comienzos del siglo XX

Identity, juxtaposition and resistance: three categories to understand the Latin-American piano music of the beginning of 20th century

Mónica Tobo Medivelso

Música, educación musical y género.

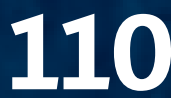
Un estudio sobre la participación de la mujer de la zona andina nariñense en la interpretación (instrumental y vocal), la educación musical y la composición Music, musical education and gender A study on the participation of women in the Andean area of Nariño in the interpretation (instrumental and vocal), music education and composition

Lyda Tobo Mendivelso, José Menandro Bastidas España

\section{Música en clave}

Creación orquestal de la obra para piano Fantasía Romántica de Maruja Hinestrosa

Orchestral creation about Maruja

Hinestrosa's Fantasía Romántica concert for piano and orchestra

Julián Augusto Castro Gaviria,

Anthony Sebastián Chunganá, Andrés Felipe Gómez

\section{Separata}

Fantasía Romántica Sobre Aires Colombianos Concierto para piano y orquesta de Maruja Hinestrosa

Orquestación: Julián Augusto Castro Gaviria

Convocatoria Revista No. 9

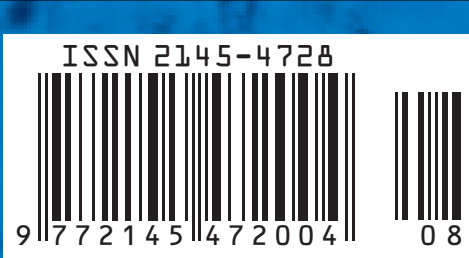

